\title{
TURNING POINT
}

\section{Russell Neches}

Trained as a physicist, Russell Neches is now pursuing a PhD in microbial ecology. A believer in the do-it-yourself approach, Neches, of the University of California, Davis, wrote an algorithm to find a $\mathrm{PhD}$ adviser and manufactures lab supplies cheaply with a three-dimensional (3D) printer.

\section{Have you always been a do-it-yourselfer?} Yes. I had a unique high-school experience at the Putney School in Vermont. It was a working farm. I was one of 180 students growing all of our own food. That set the stage for my pursuit of practical, hands-on education.

Was your undergraduate experience similar? I wanted something like my high school, but more sophisticated. I went to Northeastern University in Boston, Massachusetts, and switched majors three times, but not because I was lost. A programme with all the computing and mathematics skills I was after did not exist, so I cobbled together those skills first in the computer-engineering programme, then in computer science, and graduated in physics.

How did you go from physics to microbiology? I came to the University of California, Davis, as a physics student, but I wanted more autonomy than I would have on a big research project such as the Large Hadron Collider. I absolutely did not want to work on weapons, so that did not leave many options. I decided to expand my search to see if there was a project that was not immediately obvious to me.

\section{How did you go about that?}

I co-opted some e-mail-filtering software that classifies similarities between texts, such as word frequencies. I trained it using two groups of papers - my own and papers I thought were interesting, and papers I did not like. I then used the software to classify papers written by Davis faculty members as interesting or not interesting. I had trained the software on pure physics, but it kept giving me papers on ecology and genomics because there are mathematical similarities between the fields, such as how they describe the time evolution of spatial patterns for either particles or organisms. I was stunned. I was led to papers on metagenomics, and to Jonathan Eisen, who studies microbial ecology and evolution.

\section{Was it a good move for you?}

Definitely. Soon after I arrived in Eisen's lab, I got the opportunity to visit the volcanic Kamchatka Peninsula in Russia, which is like

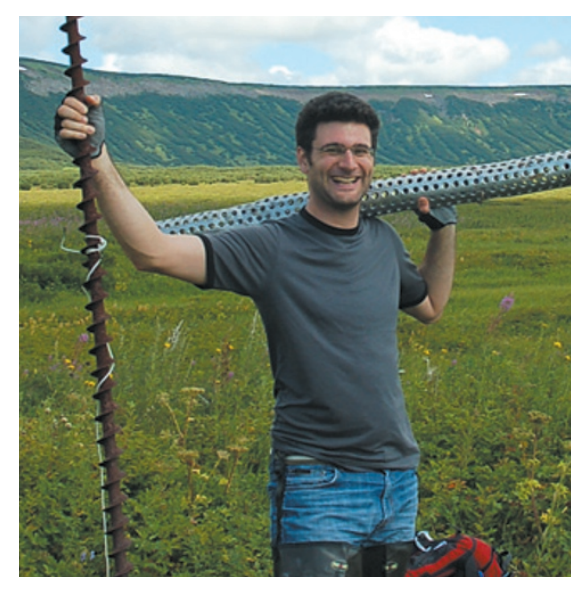

Disneyland for microbial ecologists because there are so many different types of microbial metabolism in the region. I spent lots of time hiking around the Mutnovsky volcano, which erupted violently in 2000, sterilizing the region. I got more and more interested in figuring out how microbes got there.

\section{How have you used 3D printing?}

I am working in this weird space between ecology, genomics, maths and molecular biology, so there are not a lot of ready-made tools. If tools do exist, they are usually too expensive or not flexible enough for my needs. So I bought a $3 \mathrm{D}$ printer to build tools for a fraction of the cost. For example, I printed an adapter that turns an automatic hammer into a bead grinder, which allowed me to do fieldbased DNA extraction. I have also used it to prototype a zero-gravity microtitre plate for use in Project MERCURRI, a citizen-science project about microbes on the International Space Station. Oddly, the thing that struck a nerve among readers of my blog was when I printed gel combs - pieces of plastic used in gel electrophoresis - for pennies compared to their usual US\$50 price tag.

How do you use social media to interact with the scientific community?

Mainly to discuss research ideas. I used my blog and Twitter to seek input on my $\mathrm{PhD}$ project before my qualifying exams. I got informative and humbling feedback. Some professors and graduate students e-mailed me papers I would not have known to look for; others suggested stronger and simpler experimental approaches. I did a test run on a world-class stage and I got world-class comments.

INTERVIEW BY VIRGINIA GEWIN

\section{PHD STUDENTS}

\section{Early publishers thrive}

Graduate students who publish frequently are most likely to continue publishing often throughout their careers, says a study (W. F. Laurance et al. Bioscience $63,817-823 ; 2013)$. The authors looked at 182 academic biologists across four continents, examining how their publication rates for the first 10 years after their $\mathrm{PhDs}$ were affected by factors such as pre-PhD publication rate and date of first paper. The best predictor of successful publication was how often scientists published before receiving their PhDs. "Publish early, publish often," says lead author William Laurance, a biologist at James Cook University in Cairns, Australia. He advises young scientists to work with their lab heads to secure lead authorship whenever possible, and not to focus exclusively on competitive journals.

\section{PEER REVIEW}

\section{Flawed data slip through}

Peer review is failing to ensure data quality, finds a study (R. D. Chirico et al. J. Chem. Eng. Data http://doi.org/nzv; 2013). The analysis, led by the US National Institute of Standards and Technology (NIST), found that about one-third of papers submitted to five physical-chemistry journals between 2003 and 2013 contained erroneous or incomplete data, which can make it hard to replicate findings and can lead to poor regulatory decisions. Peer review does not have the capacity to evaluate the current flood of data, say co-authors Michael Frenkel and Robert Chirico, chemists at NIST in Boulder, Colorado. "The rate of errors is an elephant in the room," says Frenkel.

\section{FUNDING}

\section{Help from industry}

Companies funded $4.9 \%$ of US academic research in 2011, down less than $0.3 \%$ from 2010, finds a report published on 19 September by the US National Science Foundation (see go.nature.com/kc4g24). Medical sciences received the most industry money, at 39\%; biology received $11 \%$, agricultural sciences $5 \%$ and environmental sciences $4 \%$. Businesses including pharmaceutical, electronics and food-manufacturing firms fund academic research in part to establish relationships that allow "first pick of the good grad students", says study co-author Brandon Shackelford, owner of Twin Ravens Consulting in Austin, Texas. 